\begin{tabular}{|c|c|c|}
\hline $\begin{array}{l}\text { OPEN ACCESS } \\
\text { Vol. } 2 \text { No.2: } 20-30 \\
\text { Tahun 2019 } \\
\text { Artikel penelitian 唒 }\end{array}$ & $\begin{array}{l}\text { Jurreal Alcuatiklestari } \\
\text { E-ISSN: 2598-8204 } \\
\text { http://ojs.umrah.ac.id/index.php/akuatiklestari } \\
\text { Dol: https://doi.org/10.31629/akuatiklestari.v2i2.989 }\end{array}$ & $\frac{-}{\vdots=}$ \\
\hline
\end{tabular}

\title{
Kajian Stok Udang Putih (Penaeus merguiensis) di Perairan Senggarang Kota Tanjungpinang
}

\author{
Study of White Shrimp Stock (Penaeus merguiensis) in the Senggarang Waters of Tanjungpinang \\ City
}

\section{Irma Devi Selvia1 ${ }^{\bowtie}$, Febrianti Lestari $^{1}$, Susiana $^{1}$}

${ }^{1}$ Manajemen Sumberdaya Perairan, Fakultas Ilmu Kelautan dan Perikanan, Universitas Maritim Raja Ali Haji, Tanjungpinang, Indonesia 29111

\section{$\square$ Info Artikel:}

Diterima: 29 Januari 2019

Revisi: 12 Februari 2019

Disetujui: 29 Maret 2019

Dipublikasi: 30 Mei 2019

\section{Keyword:}

Tingkat Eksploitasi, Udang Putih, Penaeus merguiensis, Pertumbuhan, Tingkat Moratalitas

$\triangle$ Penulis Korespondensi:

Irma Devi Selvia

Manajemen Sumberdaya Perairan, Fakultas IImu Kelautan dan Perikanan,

Universitas Maritim Raja Ali Haji

Email: irmadevi0496@yahoo.com

\begin{abstract}
ABSTRAK. Penelitian ini mengenai analisis stok udang putih (Penaeus merguiensis) di Perairan Senggarang Kota Tanjungpinang. Tujuan penelitian ini adalah untuk mengetahui stok udang putih (Penaeus merguiensis) berdasarkan frekuensi panjang, identifikasi kelompok ukuran, parameter pertumbuhan, hubungan panjang bobot serta faktor kondisi, dan juga tingkat mortalitas serta laju eksploitasi pada udang di Perairan Senggarang, Kota Tanjungpinang. Penelitian ini dilakukan dengan metode random sampling sebanyak 600 ekor dengan kisaran panjang 45-178 mm yang dianalisis mengguanakan data sofware dengan aplikasi FISAT II dan regresi dari microsoft excel. Penelitian ini menghasilkan koefisien pertumbuhan (K) yang paling tinggi didapatkan dari data udang putih betina yaitu sebesar 0,88 per tahun, sedangkan untuk panjang berat udang putih jantan dan betina keduanya adalah allometrik negatif (pertambahan panjang lebih cepat daripada pertambahan bobot). Laju eksploitasi udang putih paling tiggi didapat dari data udang putih betina sebesar 0,76 per tahun. Nilai eksploitasi ini melebihi nilai eksploitasi optimum 0,5.
\end{abstract}

\begin{abstract}
This research is about the analysis of white shrimp stocks (Penaeus merguiensis) in the waters of Senggarang, Tanjungpinang City. The purpose of this study was to determine the stock of white shrimp (Penaeus merguiensis) based on length frequency, identification of size groups, growth parameters, length and weight condition and relationship factors, as well as mortality rates and exploitation rates of shrimp in Senggarang waters, Tanjungpinang City. This research was conducted with a random sampling method of 600 animals with a length range of 45-178 mm which was analyzed using software data with the application of FISAT II and regression from Microsoft Excel. This study produced the highest growth coefficient $(K)$ obtained from female white shrimp data that is equal to 0.88 per year, while the length of weights for male and female white shrimp are both allometric negative (the increase in length is faster than weight gain). The highest rate of white shrimp exploitation was obtained from female white shrimp data of 0.76 per year. This exploitation value exceeds the optimal exploitation value of 0.5 .
\end{abstract} Akuatiklestari, 2(2): 20-30. https://doi.org/10.31629/akuatiklestari.v2i2.989

\section{PENDAHULUAN}

Perairan Senggarang merupakan daerah yang termasuk wilayah Kecamatan Tanjungpinang Kota, perairan ini memiliki berbagai potensi sumberdaya, salah satunya ialah Penaeus marguiensis. Pendeus marguiensis termasuk kedalam klasifikasi udang paneid yang komoditasnya menjadi sasaran utama. Jenis P. marguiensis ini merupakan salah satu jenis dari 100 jenis udang paneid dan udang komersial penting dalam perikanan tangkap. Penangkapan udang di Perairan Senggarang secara terus menerus dilakukan oleh nelayan, hal ini dikarenakan untuk memenuhi permintaan pasar terhadap udang. Nelayan cenderung melakukan penangkapan tanpa memperhatikan ukuran udang tersebut, sehingga ukuran udang yang tertangkap masih berukuran kecil dan dalam kondisi belum layak ditangkap. Selain itu, nelayan melakukan aktivitas penangkapan yaitu kapan dan dimana saja tanpa memperhatikan adanya musim pemijahan, sehingga dikhawatirkan dapat mempengaruhi sumberdaya pada P. marguiensis di Perairan Senggarang. 
Penelitian ini bertujuan untuk mengetahui stok udang berdasarkan frekuensi panjang, identifikasi kelompok ukuran, parameter pertumbuhan, hubungan panjang bobot serta faktor kondisi dan mengetahui tingkat mortalitas serta laju eksploitasi pada udang di Perairan Senggarang, Kota Tanjungpinang.

\section{BAHAN DAN METODE}

\subsection{Waktu dan tempat}

Penelitian ini dilaksanakan pada Bulan Mei sampai dengan Bulan Oktober 2018 yang berlokasi di Perairan Senggarang Kota tanjungpinang. Peta lokasi dapat dilihat pada Gambar 1.

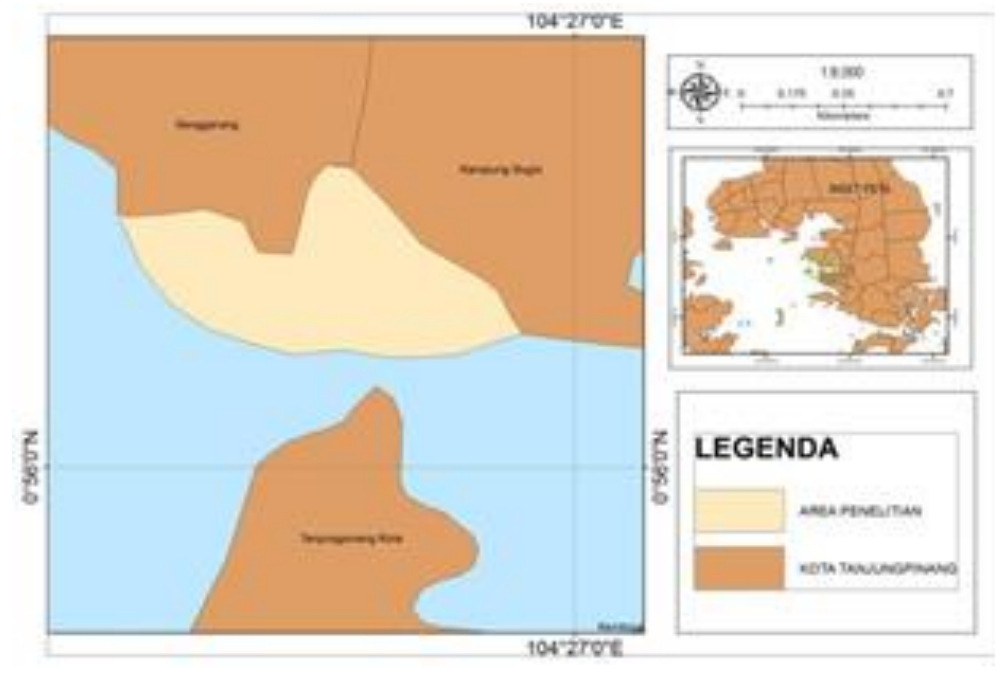

Gambar 1. Peta Lokasi Penelitian

\subsection{Alat dan Bahan}

Peralatan yang digunakan dalam penelitian terdiri dari: kamera yang digunakan untuk mengambil dokumentasi objek penelitian, alat tulis dan lembar kerja untuk mencatat hasil tangkapan dan wawancara, jangka sorong untuk mengukur panjang udang, timbangan digital untuk menimbangan hasil udang, dan sampel udang sebagai objek penelitian

\subsection{Prosedur Penelitian}

Tahapan penelitian terdiri dari penentuan lokasi penelitian, pengambilan data, serta pengolahan dan analisis data. Penelitian dilakukan melalui survei lapang. Penentuan lokasi penelitian dilakukan menggunakan metode Random sampling. Terdapat satu lokasi penelitian, yaitu tempat penangkapa udang. Lokasi penelitian merupakan tempat nelayan mendaratkan udang. Penentuan sampel di lakukan 12 kali dalam 6 bulan dengan banyak sampel 50 ekor/ pengamblan sampel (Syakila, 2009).

\subsection{Teknik Pengambilan Data}

Data yang dikumpulkan berupa data primer yang dilakukan dengan cara mengambil sampel udang. Data yang diperoleh berupa data panjang total dan bobot udang. Pengumpulan data sekunder dilakukan dengan mengumpulkan data dari intansi terkait seperti kantor kelurahan senggarang mengenai data monografi.

\subsection{Pengolahan dan Analisis Data}

Untuk menganalisis data sofware yang digunakan adalah FISAT II Ver 1.1.0 yang dikeluarkan oleh FAOICLARM, Regresi dan juga dilakukan dengan cara manual. Analisis data yang dilakukan mencakup sebagai berikut:

\section{Distribusi Frekuensi Panjang}

Data yang digunakan dalam penentuan distribusi frekuensi panjang dalah data panjang total dari udang yang didaratkan di Senggarang. Distribusi frekuensi panjang ini didapatkan dengan menentukan selang kelas, nilai tengah kelas dan distribusi frekuensi panjang yang telah ditentukan dalam selang kelas yang sama diplotk an dalam sebuah grafik, (Susilawati, 2013).

\section{Identifikasi Kelompok Ukuran}

Identifikasi menggunakan metode bhattacarya atau secara grafik. Metode ini pada dasarnya terdiri atas pemisahan sejumlah distribusi normal, masing-masing mewakili suatu kohort udang dari distribusi keseluruhan dimulai dari sebelah kiri distribusi total, (Susilawati, 2013). 


\section{Parameter Pertumbuhan $(\mathrm{L} \infty, \mathrm{K})$ dan to}

Di dalam pendugaan parameter pertumbuhan terhadap udang putih dilakukan dengan menggunakan rumus pertumbuhan, (Spare \& Venema, 1999). Persamaan perumbuhan Von Bertalanffy dapat dinyatakan sebagai berikut:

$$
L_{t}=L_{\infty}\left(1-\exp ^{-k(t-t o)}\right)
$$

Untuk menduga umur teoritis pada saat panjang sama dengan nol dapat diduga secara terpisah dengan menggunakan persamaan empiris pauly, (Pauly, 1983):

$$
\log \left(-t_{o}\right)=0.3922-0.2752 \log \left(L_{\infty}\right)-1.0382 \log k
$$

Keterangan:

$L_{t} \quad=$ Panjang udang pada saat umur t (satuan waktu)

$L_{\infty} \quad$ = Panjang maksimum secara teoriti (pnjang asimtotik)

$\mathrm{K}=$ Koefisien laju pertumbuhan (persatuan waktu)

$t_{o} \quad=$ Umur teoritis pada saat panjang sama dengan nol

\section{Hubungan Panjang Bobot}

Untuk mengukur hubungan panjang-berat masing masing spesies udang digunakan rumus yang umum digunakan adalah sebagai berikut (Efendie, 2002):

$$
\mathrm{W}=\mathrm{aL}^{\mathrm{b}}
$$

Keterangan:

$\mathrm{W}=$ Berat

$\mathrm{L}=$ Panjang

$\mathrm{a}=$ Intersep (perpotongan kurva hubungan panjang-berat dengan sumbu y)

$\mathrm{b}$ = Penduga pola pertumbuhan panjang-berat

\section{Faktor Kondisi}

Menurut Effendie (2002), dimana untuk faktor kondisi dapat dihitung berdasarkan panjang dan berat udang. Jika nilai $b \neq 3$ (tipe pertumbuhan bersifat allometrik), maka rumus yang digunakan adalah sebagai berikut:

$$
K=\frac{W}{a L^{b}}
$$

Keterangan:

$\mathrm{K}=$ Faktor kondisi

$\mathrm{W}=$ Bobot udang (gram)

$\mathrm{L}=$ Panjang

$\mathrm{a}$ dan $\mathrm{b}=$ Konstanta

\section{Mortalitas dan Laju Eksploitasi}

Dalam mengukur laju mortalitas alami (M) dapat diduga dengan menggunakan rumus empiris dari Sperre \& Venema (1999) adalah sebagai berikut:

$$
\ln \mathrm{M}=-0,0152-0,279 \ln L_{\infty}+0,6543 * \ln \mathrm{K}+0,463 * \ln \mathrm{T}
$$

Keterangan:

$\mathrm{M} \quad=$ Mortalitas alami

$\mathrm{L}^{\infty} \quad$ = panjang asimtotik pada persamaan pertumbuhan Von Bertalanffy

$\mathrm{K}=$ Koefisien pertumbuhan pada persamaan pertumbuhan Von Bertalanffy

$\mathrm{T} \quad=$ Rata-rata suhu permukaan air $\left({ }^{\circ} \mathrm{C}\right)$

Sedangkan untuk mengukur laju mortalitas penangkapan (F) dapat ditentukan dengan:

$$
\mathrm{F}=\mathrm{Z}-\mathrm{M}
$$

Dan menurut Sperre dan Venem (1999), untuk mengukur eksploitasi ditentukan dengan membandingkan mortalitas penangkapan (F) terhadap mortalitas (z).

$$
E=\frac{F}{Z}
$$




\section{HASIL DAN PEMBAHASAN}

\section{3.l. Udang Putih (Penaeus merguiensis) Di Perairan Senggarang}

\section{Deskripsi Udang Putih (Penaeus merguiensis)}

Udang yang berada dilokasi penelitian dilihat dari morfologi udang Penaeus merguiensis betina yang tertangkap mempunyai ukuran mulai dari 45-178 mm sedangkan untuk udang jantan memiliki ukuran mulai dari 54- $149 \mathrm{~mm}$, dimana udang putih ini terdiri dari bagian kepala dan bagian dada yang menyatu disebut juga dengan cephalothrox, dan bagian tubuh sampai ekor disebut dengan adomen. Memiliki antena, rostum yang runcing dengan dilengkapi duri - duri kecil dan bagian kepla ditutupi oleh kulit kepala atau disebut dengan karapaks. Pada bagian perut udang terdapat ruas-ruas, 5 pasang kaki renang pada bagian perut dan terdapat 5 pasang kaki jalan pada bagian dada. Hal ini seperti yang dikatakan oleh Bitner \& Ahmad (1989). Morfologi udang yang ditangkap oleh nelayan dengan udang pada literatur pada Gambar 2.

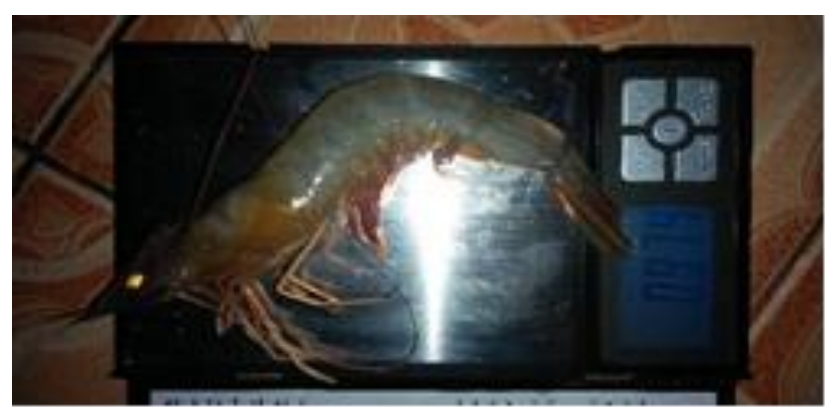

Udang Contoh Penelitian

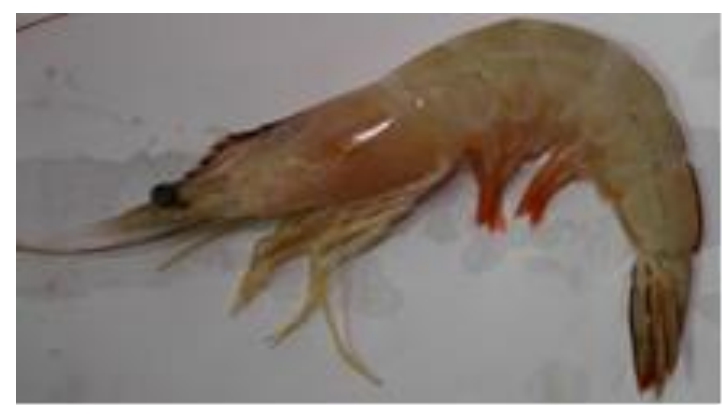

Udang Contoh Literatur

Gambar 2. Udang Putih (Penaeus merguiensis)

\section{Penangkapan dan Alat Tangkap}

Hasil dari wawancara yang dilakukan dengan nelayan yang menangkap udang putih (Penceus merguiensis) para nelayan menangkap menggunakan pompong yang berukuran kurang dari 1 GT dengan alat tangkap yang digunakan adalah pukat 2, waktu penangkapan yang dilakukan nelayan setiap hari dan ada beberapa nelayan yang tidak turun kelaut kecuali hari kamis, biasanya dilakukan pada malam hari sampai dengan pagi hari. Hasil dari tangkapan ini para nelayan menjualnya langsung dipasar sengarang, dan apabila ada yang ingin membeli langsung sebelum dibawa ke pasar maka nelayan tersebut pun akan menjualnya.

\subsection{Kajian Stok Udang Putih (Penaeus merguiensis) Sebaran Frekuensi Panjang}

Panjang total minimum dan panjang total maksimum P. merguiensis yaitu $45 \mathrm{~mm}$ dan $178 \mathrm{~mm}$. Sebaran ukuran panjang total P. merguiensis selama penelitian secara keseluruhan dan berdasarkan jenis kelamin disajikan pada Gambar 3. dan 4 .

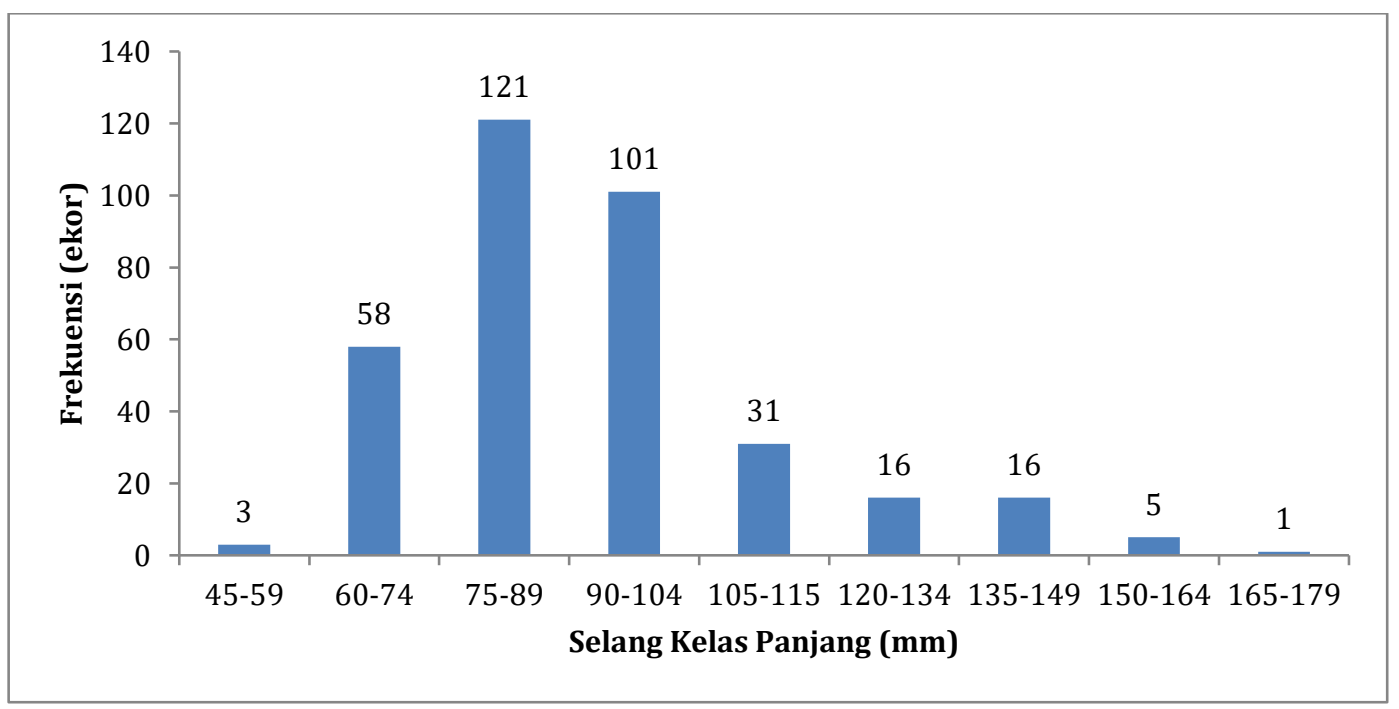

Gambar 3. Sebaran Frekuensi Panjang Total P. merguiensis Betina 


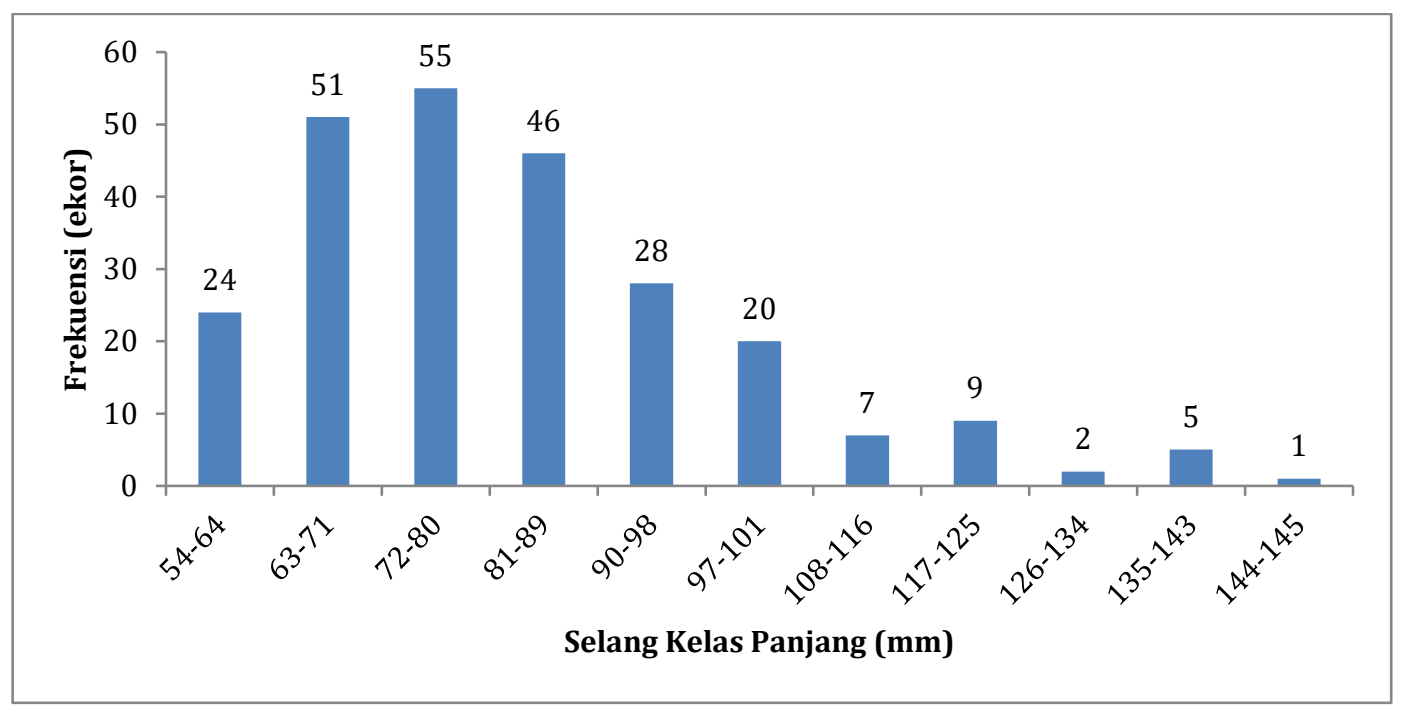

Gambar 4. Sebaran Frekuensi Panjang Total P. merguiensis Jantan

Struktur ukuran panjang pada Gambar 3. P. Merguiensis betina yang tertangkap pada Perairan Senggrang memiliki panjang yang terletak pada selang kelas 45-59 mm sampai dengan 165-179 mm, sedangkan P. merguiensis Jantan pada Gambar 4. yang tertangkap pada Perairan Senggarang memiliki panjang yang terletak pada selang kelas 54-64 mm sampai dengan 144-154 mm. Dari data penelitan 600 ekor sampel P. merguiensis yang diteliti terdapat jumlah P. merguiensis betina sebanyak 352 ekor dan banyaknya P. merguiensis jantan berjumlah 248 ekor. Hasil dari penelitian yang dilakukan Tirtanadu et al. (2017) jumlah udang P. merguiensis yang tertangkap lebih banyak betina dibandingkan dengan jenis $P$. merguiensis jantan yaitu sebanyak 548 ekor untuk betina dan 392 ekor dari jumlah 940 ekor. Dengan ini menunjukkan adanya perbedaan sebaran ukuran panjang, dimana $P$. merguiensis betina lebih besar dari pada $P$. merguiensis jantan. Menurut Saputra et al. (2009), apabila jantan dan betina seimbang atau betina lebih banyak dapat diartikan bahwa populasi tersebut masih ideal untuk mempertahankan kelestarianya. Hasil dari frekuensi keseluruhan ini dapat dilihat ukuran udang yang sering tertangkap diperairan Senggarang ialah udang yang kecil, dimana ukuran yang sering tertangkap untuk udang betina sekitar dengan panjang 75-89 mm dan untuk udang jantan yang sering tertangkap dengan panjang 72-80 mm. Hal ini dikarenakan pada udang dewasa memperlihatkan ukuran-ukuran untuk umur, karena udang betina lebih besar dari pada udang jantan pada umur yang sama (Budianto, 2012).

\section{Parameter Pertumbuhan $\left(\mathrm{L}^{\infty}, \mathrm{K}\right)$ dan $\mathrm{t} 0$}

Data sebaran frekuensi P. Merguiensis perbulannya dimana ukuran panjang yang berbeda-beda tiap bulannya, pada bulan mei modus panjang total betina yaitu $90-104 \mathrm{~mm}$ dan untuk P. Merguiensis jantan memiliki modus panjang total 63-71 mm, tetapi pada sampling bulan selanjutnya ukuran panjang pada bulan mei berubah dan ukuran panjang yang lebih besar bergeser mejadi lebih tinggi dan hal yang sama pada bulan-bulan selanjunya, hal ini diduga adanya pertumbuhan panjang pada $P$. Merguiensis. Sehingga untuk jenis $P$. Merguiensis betina pada bulan juli dan September memiliki kelompok kelas panjang terbanyak dibandingkan dengan bulan lainnya, bahkan pada bulan oktober hanya memiliki tiga kelompok kelas panjang. Kemudian untuk sebaran P. Merguiensis jantan yang memiliki ukuran panjang yang berbeda-beda tiap bulannya, yaitu pada bulan September memiliki kelompok panjang kelas terbanyak dibandingkan dengan bulan lainnya. Sedangkan penelitian yang dilakukan oleh Wahyuni et al. (2017) pergeseran modus panjang total terjadi saat sampling kelima dari lima sampling yang dilakukan, karena diduganya adanya perubahan sampling kelima. Dapat juga dilihat dari Gambar 5. yaitu masuknya individu baru ataupun hilangnya individu ukuran dewasa, dan juga dari tiap bulannya memiliki beberapa kelompok umur yang berbeda, dimana untuk P. Merguiensis jantan memiliki kelompok ukuran tertinggi pada bulan Agustus dan September dimana tiap bulannya memiliki dua kelopok ukuran dengan panjang nilai tengah tertinggi sepanjang 81 dan $141 \mathrm{~mm}$. Sedangkan untuk $P$. Merguiensis betina memiliki kelompok ukuran terbanyak pada bulan Juli sebanyak tiga kelompok umur mulai dari panjang $67 \mathrm{~mm}, 112 \mathrm{~mm}$ dan $139 \mathrm{~mm}$. 

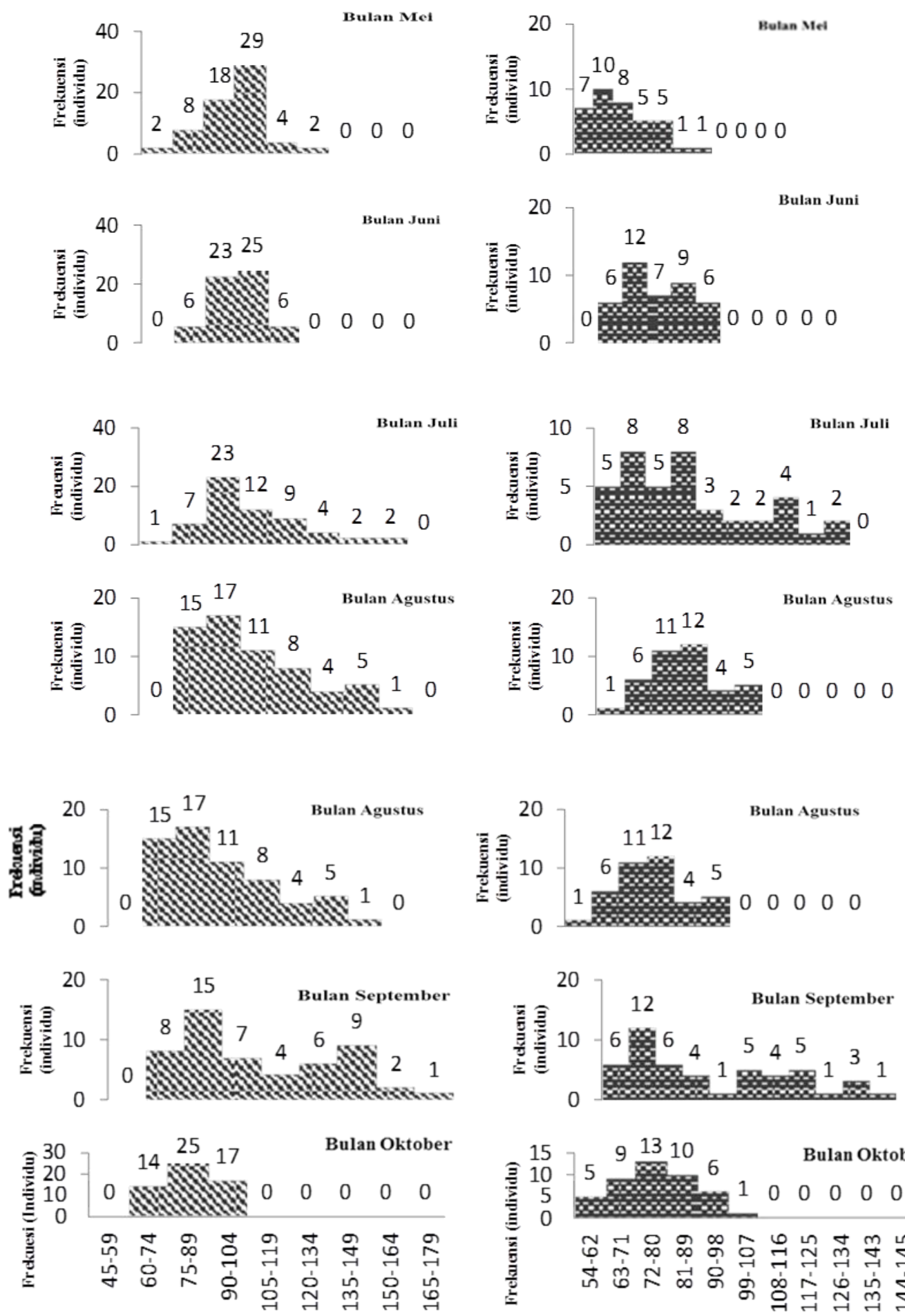

Selang Panjang Kelas (mm)

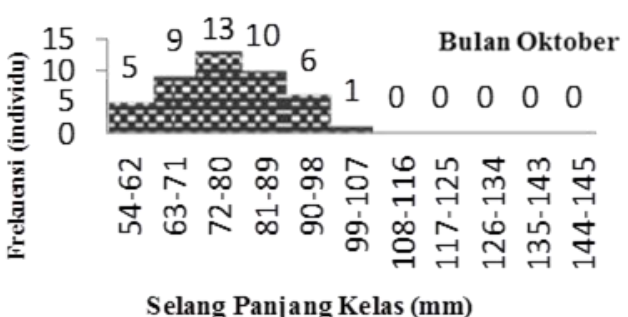

Gambar 5. Grakfik frekuensi P. merguiensis Betina dan Jantan perbulan
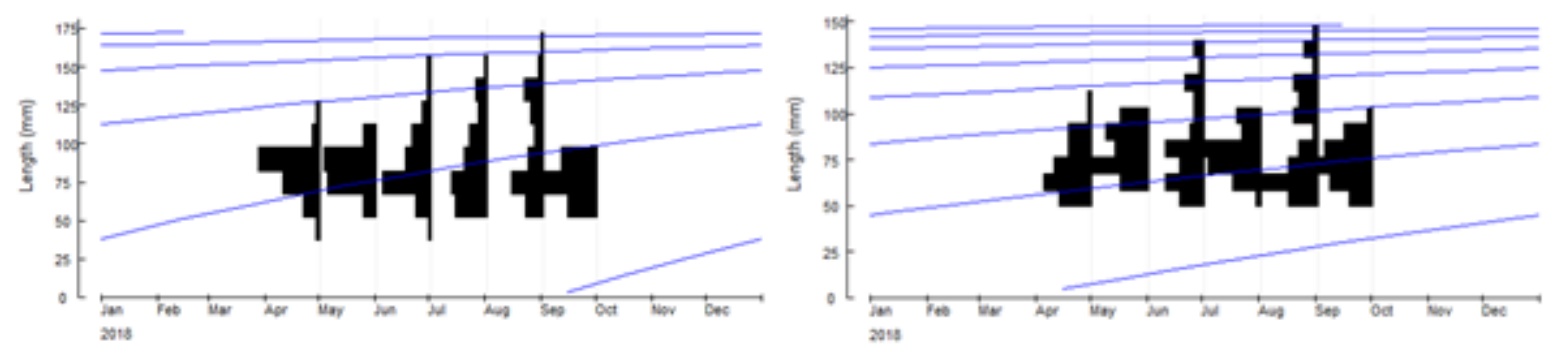

Gambar 6. Grafik VBGF P. merguiensis Betina dan Jantan 
Dari Gambar 6. maka dapat dilihat lebih jelas adanya pergerakan pertumbuhan dari P. merguiensis pada tiap bulannya. Dimana untuk P. Merguiensis betina memiliki pertumbuhan paling panjang pada bulan September memiliki panjang maksimal total sepanjang $178 \mathrm{~mm}$. Sedangkan pada P. merguiensis jantan memiliki panjang maksimal $154 \mathrm{~mm}$ pada bulan yang sama seperti $P$. merguiensis betina. Dari gambar di atas maka dapat dlihat pada $P$. merguiensis pada pertengahan bulan September dimana dapat dilihat panjang udang sama dengan nol yang mengartikan adanya individu baru. Sedangkan hasil penelitian yang dilakukan oleh Nurdin \& Kembaren (2015) di perairan Sampit dan sekitarnya, Kalimantan Tengah terjadi pada pertengahan bulan oktober. Perbedaan ini dimungkinkan dengan kondisi perairan yang berbeda dan cukup jauh antara perairan Senggarang, Tanjungpinang dengan perairan Sampit, Kalimantan Tengah. Untuk hasil analisis dari parameter pertumbuhan P. merguiensis yaitu koefisien pertumbuhan (K) dan panjang infinitif $\left(\mathrm{L}^{\infty}\right)$ serta umur teoritis udang pada saat panjang sama dengan nol yang di sajikan pada Tabel 1.

Tabel 1. Parameter Pertumbuhan Berdasarkan Model Von Bertalanffy (Lo,K, dan t0)

\begin{tabular}{clccc} 
No & & Parameter & Jantan & Betina \\
$\mathbf{1}$ & K (pertahun) & 0,80 & 0,88 \\
$\mathbf{2}$ & L $\infty(\mathrm{mm})$ & 154 & 178,50 \\
$\mathbf{3}$ & t0 & $-0,109$ & $-0,1698$ \\
\hline
\end{tabular}

Sumber: Data Primer (2018)

Tabel 1. dapat dilihat yaitu panjang maksimum P. merguiensis jantan yang tertangkap sepanjang $149 \mathrm{~mm}$, dan panjang maksimum betina $178 \mathrm{~mm}$. Sedangkan hasil dari panjang asimtotik (L ${ }^{\infty}$ ) pada jantan sepanjang $154 \mathrm{~mm}$, dan hasil dari betina yaitu sebesar 178,5 mm, panjang ini menunjukkan untuk jenis jantan dan betina lebih kecil dibandingkan dengan panjang ${ }^{\infty}$. Koefisien pertumbuhan (K) P. Merguiensis betina adalah 0,88 pertahun kemudian untuk jenis $P$. merguiensis jantan sebesar 0,80 pertahun. Sedangkan hasil penelitian yang dilakukan oleh Saputra et al. (2013) yaitu panjang infinity ( $\mathrm{L}^{\infty}$ ) dari udang P. merguiensis betina di perairan Cilacap yaitu sebesar 63,579 mm, sedangkan untuk panjang kerapas udang P. merguiensis jantan didapatkan hasil sebesar 60,421 mm. Yang berarti panjang ukuran betina lebih panjang dibandingkan dengan ukuran pajang Jantan. Peredaan nilai yang diperoleh ini dapat disebabkan oleh berbagai macam faktor internal diantaranya yaitu kemungkinan adanya parasit, penyakit dan faktor eksternal yaitu adanya perbedaan kuaitas perairan dan ketersediaan makanan. Berdasarkan persamaan pertumbuhan $P$. merguiensis dapat diperoleh kurva pertumbuhan. Dengan cara memplotkan umur (bulan) dan panjang teoritis (mm). Sehingga untuk ukuran pada P. merguiensis betina sampai berumur 43 bulan, dan untuk jenis P. merguiensis jantan sampai berumur 39 bulan. Kurva pertumbuhan pada P. merguiensis dapat dilihat pada Gambar 7.
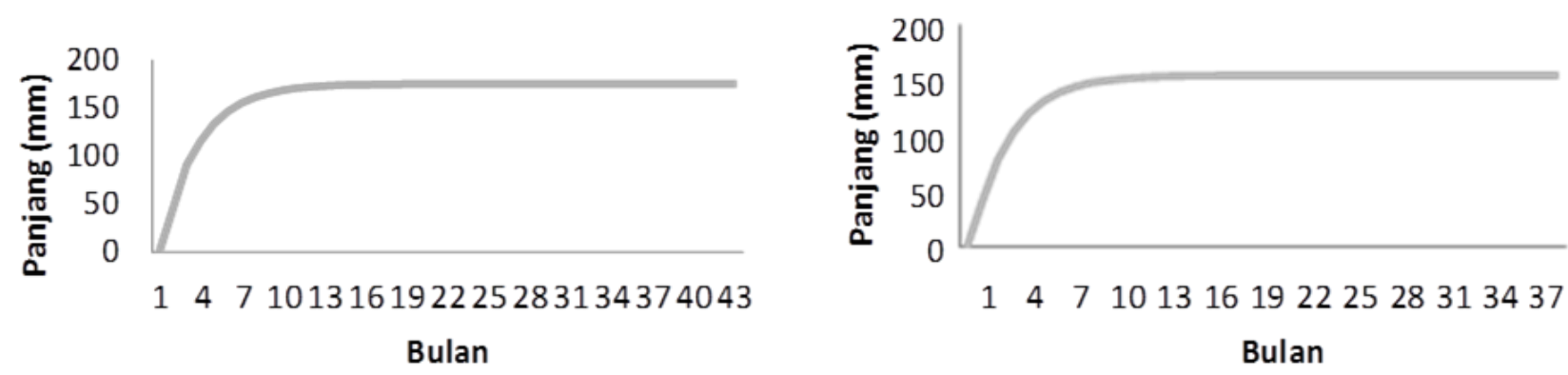

Gambar 7. Kurva Pertumbuhan P. merguiensis Betina dan Jantan

Berdasarkan dari Gambar 7. terlihat bahwa laju pertumbuhan Kurva pertumbuhan pada P. merguiensis betina selama rentang hidupnya tidak sama. Dari kurva pertumbuhan ini dapat dilihat yaitu P. merguiensis betina yang tertangkap mulai dari $45 \mathrm{~mm}$ berumur \pm 3 bulan dan untuk P. merguiensis jantan yang tertangkap mulai berumur \pm 3 bulan dengan panjang $54 \mathrm{~mm}$. Dari kurva tersebut dapat dilihat pertumbuhan pada P. merguiensis semakin lambat seiring dengan bertambahnya umur sampai mencapai panjang asimtotik dimana $P$. merguiensis tidak bertambah panjang lagi. Laju pertumbuhan tidak sama selama rentang hidupnya, P. merguiensis yang berumur muda memiliki laju pertumbuhan lebih cepat dibandingkan udang yang berumur tua. 
Hubungan Panjang Berat Udang Putih (Penaeus merguiensis) Betina dan Jantan

Tabel 2. Hasil Perhitungan Panjang dan Bobot P. merguensis betina dan Jantan

\begin{tabular}{ccccc} 
No & Komponen & Betina & Jantan & Keterangan \\
1 & $\mathrm{~N}$ & 352 & 348 & Pola pertumbuhan \\
2 & $\mathrm{a}$ & 1,7505 & 1,7411 & (setelah uji t \\
3 & $\mathrm{~b}$ & 0,3301 & 0,3402 & dengan $(\alpha=0,05)$ \\
4 & $\mathrm{R}^{2}$ & 0,9477 & 0,9639 & bersifat allometrik \\
5 & $\mathrm{~W}=\mathrm{a}$ & $1,7505^{*}$ & $1,7411^{*}$ & negatif \\
\hline
\end{tabular}
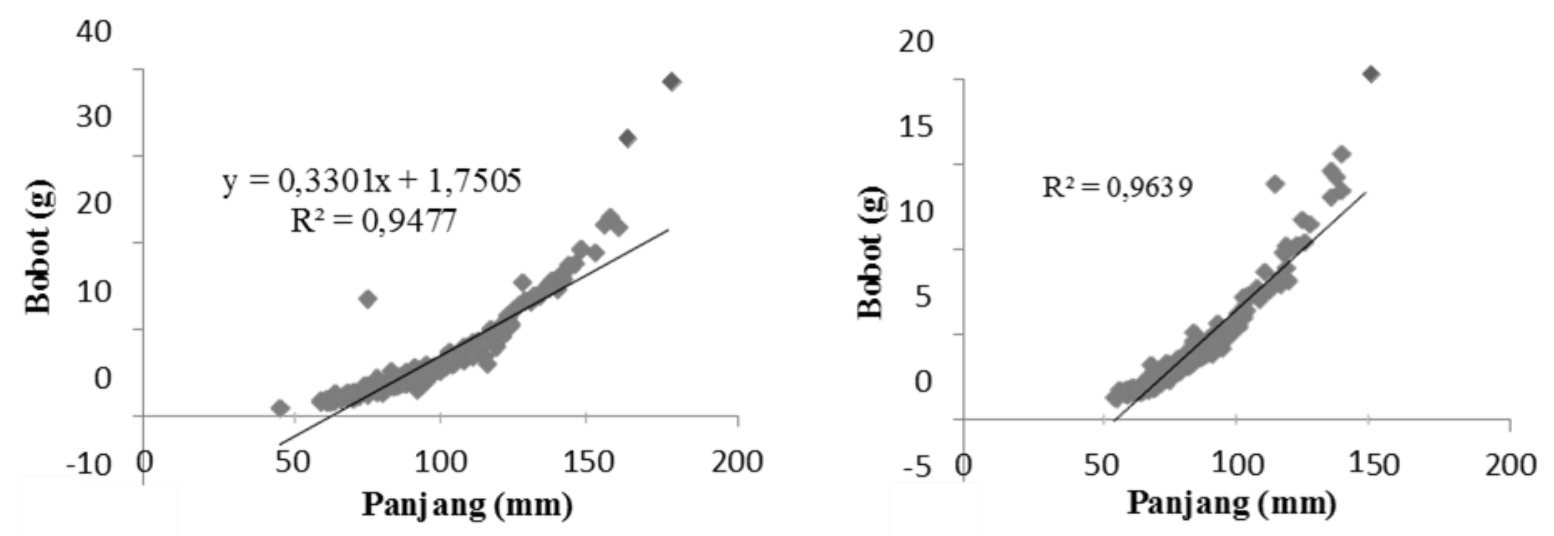

Gambar 8. Hubungan Panjang Bobot P. merguensis Betina dan Jantan (Data Primer 2018)

Dari nilai b yang diperoleh dan telah dilakukan uji t $(\alpha=0,05)$ diketahui bahwa P. merguensis betina memiliki pola pertumbuhan alometrik negatif, yang berati pertambahan panjang lebih cepat dibandingkan pertambahan bobot. Hal ini ditegaskan oleh Effendie (2002), dimana ikan dengan pola pertumbuhan allometrik negetif apabila b<3. Hasil yang diperoleh berdasarkan penelitian yang dilakukan oleh Saputra et al (2013) untuk jenis udang P. merguensis jantan memiliki sifat pertumbuhan alometrik negatif sedangkan untuk pertumbuhan jenis betina memiliki sifat pertumbuhan isometrik. Namun untuk hasil dari perairan senggarang memiliki kesamaan antara P. merguensis jantan dan udang putih betina yaitu keduanya memiliki sifat pertumbuhan alometrik negatif seperti penelitian yang dilakukan oleh Tirtadanu dan Ernawati (2016) di perairan utara Jawa Tengah yaitu allometrik negatif. dimana pertumbuhan panjang lebih cepat dibandingkan dengan pertambahan bobot. dan hasil penelitian di beberapa perairan di Indonesia, diantaranya adala $\mathrm{h}$ di Jawa (Wedjatmiko dan Yuiani, 2003). Menurut Fauzi et al. (2013) sifat pertumbuhan ini dipengaruhi oleh ketersediaan makanan dan suhu perairan, maka dari itu pada tiap tiap perairan memiliki hasil yang berbeda-beda.

\section{Faktor Kondisi}

Dari Gambar 9. Di bawah ini memperlihatkan nilai dari faktor kondisi P. merguensis betina pada setiap bulan tidak terjadi variasi temporal yang tidak terlalu jauh bahkan hampir sama. Nilai faktor kondisi tertinggi terjadi pada bulan September sebesar 1,95 sedangkan untuk nilai terendah yaitu sebesar 1,1l yang terjadi pada bulan Oktober. Hal ini menunjukkan P. merguensis betina dari waktu yang diamati dalam kondisi baik yaitu dalam keadaan baik dan gemuk (kurang pipih). Dan untuk jenis P. merguensis jantan nilai dari faktor kondisi tertinggi terletak pada bulan september 1,95 tetapi untuk nilai terendah berbeda dari betina yaitu untuk jenis jantan terletak pada bulan Mei dengan nilai sebesar 1,10. Hal ini sesuai dengan pernyataan Effendie (2002), yaitu apabila nilai K antara 1-3 menunjukkan badan ikan dalam keadaan kurang pipih. Hal ini menyebabkan kemontokan ikan kurang dikarenakan pengaruh makanan, umur, jenis kelamin dan kematangan gonad. Pertumbuhan ini disebut dengan pertumbuhan allometrik karena nilainnya <3 menunjukkan keadaan ikan kurus dimana pertambahan panjang lebih cepat dari pertambahan beratnya. 

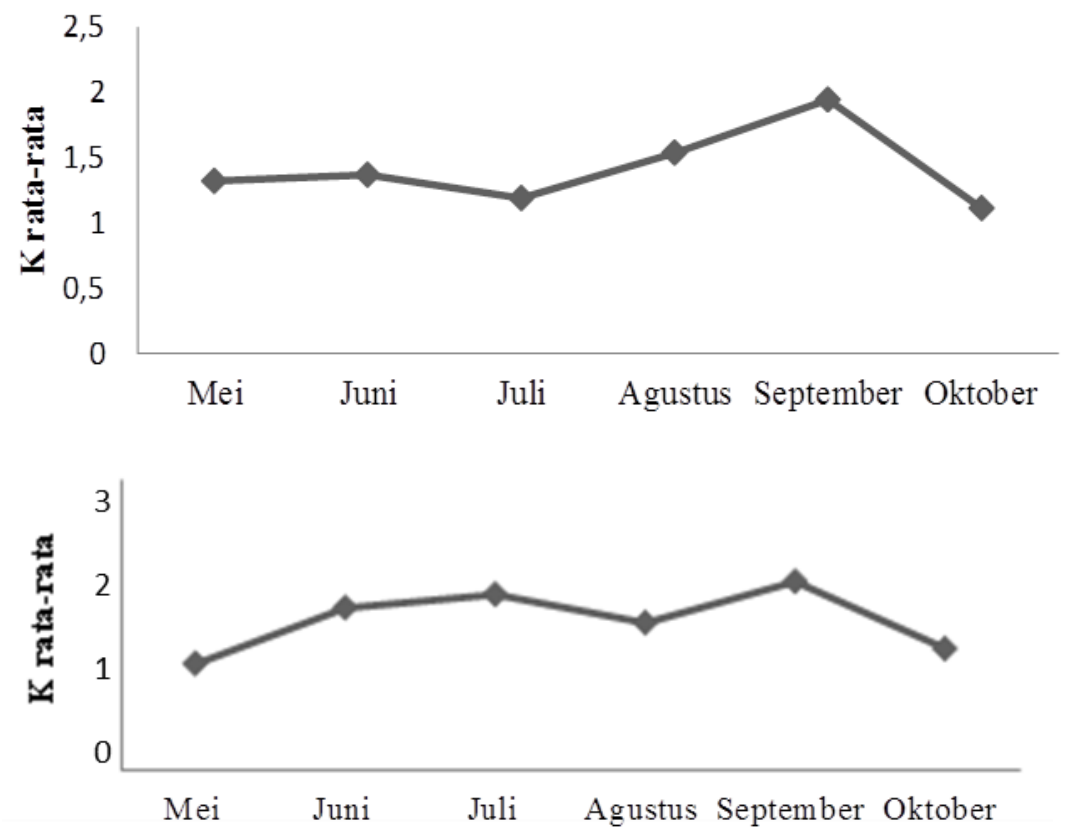

Gambar 9. Faktor kondisi P. merguensis betina (atas) dan jantan (bawah)

Berdasarkan hasil diteliti oleh Sari et al. (2017) yang di lakukan pada perairan kendal dapat dilihat nilai k yang diperoleh antara jantan yaitu 1,0939 dan untuk betina sebesar 1,0963 maka dapat dibandingkan dengan penelitian yang dilakukan pada perairan Senggarang memiliki nilai yang tidak terlalu jauh yaitu berkisaran $\pm 1-2$ yang mengartikan nilai K 1 - 3 mengaritikan dimana ukuran udang dalam keadaan kurang pipih. Dan penelitian lain yang dilakukan oleh Devi et al. (1983), udang P.indicus yang merupakan kekerabatan dari P. merguensis di daerah Chocin Back water menunjukkan factor kondisi jantan dan betina sebesar 0,96 dan 1,23 yang memiliki nilai 3 seperti di perairan Senggarang. Hidayat et al. (2013) menjelaskan udang memiliki sifat kanibalisme yaitu suka memangsa sesama jenis, sifat tersebut dapat muncul bila udang mengalami stress atau pakan yang diberikan kurang. Menurut Saputra \& Sulistyawati (2009), nilai Kn tidak berarti apa-apa jika dilihat sendiri sebagai angka tunggal. Jika dibandingkan dengan individu lainnya atau kelompok atau ukuran dengan ukuran lain yang berasal dari berbagai lokasi yang berbeda.

\section{Mortalitas dan Laju Eksploitasi}
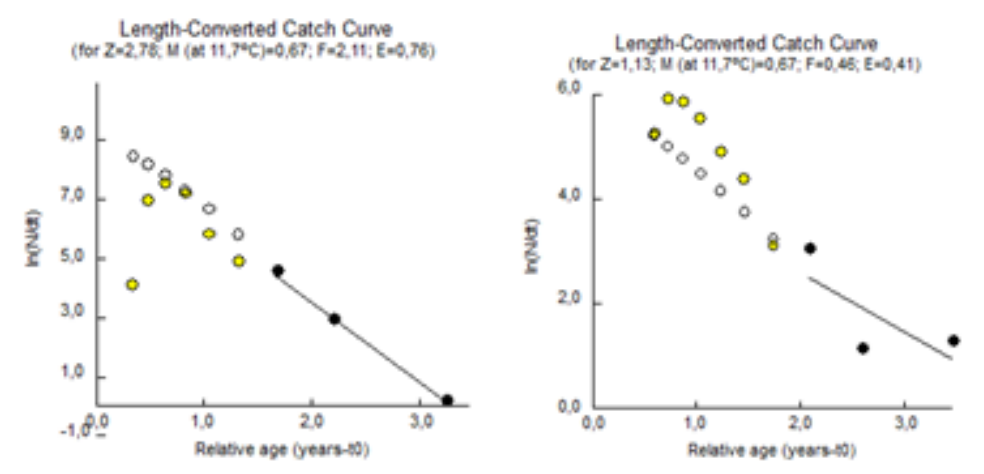

Gambar 10. Kurva Hasil Tangkapan P. merguensis Betina (kiri) dan P. merguensis Jantan (kanan)

Kurva hasil tangkapa pada P. merguensis dapat dilihat dari Gambar 10. dimana hasil dugaan mortalitas total, alami dan penangkapan serta laju eksploitasi atas menunjukkan bahwa P. merguensis betina memiliki laju mortalitas alami (M) 0,67 pertahunnya dan memiliki laju mortaitas (Z) sebesar 2,78 dan mortalitas penangkapan (F) 2,1l pertahun. Dari hal tersebut dapat dilihat bahwa M lebih kecil dibandingkan F, hal ini menunjukan bahwa tingkat kematian P. merguensis betina secara alami lebih sedikit dibandingkan P. merguensis betina yang tertangkap. Besarnya nilai laju dari eksploitasi yaitu sebesar $76 \%$ yang mengartikan bahwa $76 \%$ dari mortalitas total disebabkan oleh eksploitasi. Sedangkan untuk besarnya M P. merguensis jantan sebanyak 0,67 dalam tahunnya dengan $F$ sebesar 0,46 pertahun, maka $Z$ dari $P$. merguensis jantan dapat dilihat jumlah M lebih besar dibandingkan F, jadi untuk P. merguensis jantan ini memiliki tingkat kematian lebih tinggi secara alami dibandingkan dengan cara penangkapan, karena hasil tingkat eksploitasi sebesar 44\%. Pada perairan lain yang dilakukan oleh Nurdin \& Kembaren (2015) yaitu nilai Z pada P. merguensis yang di peroleh dari perairan Sampit, Kalimantan Tengah sebesar 5,70 untuk nilai M sebesarl,93 dan untuk nilai F 3,77 sementara untuk nilai E yaitu sebesar 0,66. Dimana kedua perairan ini memiliki nilai laju eksploitasi melebihi nilai optimum. Perberdaan nilai laju kematian udang putih di masing-masing lokasi penelitian diduga kuat dipengaruhi oleh 
perbedaan besarnya upaya penangkapan yang dilakukan dan kemampuan operasional penangkapan dari alat tangkap yang digunakan. Menurut Suman \& Umar (2010), laju kematian karena penangkapan (F) tergantung dan bervariasi menurut keragaman upaya penangkapan setiap tahunnya.

Menurut Hargiyanto et al. (2015) yaitu hasil penelitian terhadap udang jerbung (P. merguensis) di perairan Dolak Arafura bahwa penyebab over fishing adalah penangkapan udang yang belum sempat memijah. Rendahnya mortalitas alami disebabkan oleh menurunnya jumlah P. merguensis yang tumbuh pada usia muda dan mengalami kematian secara alami karena diakibatkan oleh tingginya mortalitas penangkapan dapat menunjukkan dugaan terjadinya kondisi growth overfishing yaitu pada ikan berumur muda lebih banyak tertangkap sedangkan ikan berumur tua lebih sedikit, (Sperre \& Venema 1999). Menurut Wedjatmiko (2012), mengatakan bahwa udang panaeid di Indonesia sudah mengalami overfishing di semua wilayah pengelolaan perikanan (WPP) kecuali laut Banda (tidak ada data).

\section{Implikasi Pengelolaan Udang Putih (Penaeus merguiensis)}

Sebagai negara kepulauan yang memiliki potensi sumberdaya kelautan dan perikanan yang besar maka perlu adanya perencanaan serta pengelolaan sumberdaya alam sehingga dapat dimanfaatkan secara berkelanjutan. Penangkapan berlebih diartikan sebagai jumlah usaha penangkapan sedemikian tinggi sedemikian tinggi sehingga stok udang tidak mempunyai kesempatan (waktu) untuk berkembang, hal ini menyebabkan total hasil tangkapan yang lebih rendah (Sperre et al., 1983). Maka untuk mecegah terjadiya penangkapan yang berlebihan maka perlu dibutuhkannya suatu upaya pengelolaan perikanan agar sumberdaya tersebut tatap terjaga. Dalam pengolaannya tentu saja tidaklah mudah karena harus merubah keadaan yang telah ada. Sehinga kemungkinan cara yang dapat dilakukan ialah melakukan sistem pengawasan terhadap nelayan yang melakukan penangkapan dan ukuran mata jaring yang lebih diperbesar sehingga P. merguensis yang berukuran kecil/ berumur masih muda tidak ikut tertangkap serta melakukan penelitian tentang faktor-faktor yang mendukung pertumbuhan P. merguensis baik secara biologi, fisika dan kimia sehingga dapat dilakukan upaya dalam kegiatan budidaya.

\section{SIMPULAN}

Pada penelitian ini P. merguensis betina dan jantan terdiri atas 8 dan 12 kelompok umur dengan pola allometrik negatif yang berarti memiliki pertumbuhan panjang lebih cepat dibandingkan dengan pertumbuhan bobotnya. Untuk faktor kondisi pada P. merguensis terjadi perbedaan yang signifikan selama waktu penelitian ini, hal ini menunjukkan kondisi P. merguensis dalam kondisi kurang pipih (agak gemuk). Jenis P. merguensis betina laju pada mortalitas penangkapan (F) lebih besar dibandingan dengan laju mortalitas alami (M) maka dapat diketahui kematiannya lebih besar diakibatkan oleh aktifitas penangkapan dengan tingat laju eksploitasi yang telah melebihi nilai optimum. Hal ini dikarenakan $P$. merguensis yang tertangkap berumur muda, sehingga dapat diasumsikan bahwa P. merguensis betina dari Perairan Senggarang telah mengalami growth overfishing. Sedangkan untuk P. merguensis jantan nilai M lebih besar dibandingkan dengan nilai F maka tingkat kematian secara alami lebih tinggi dan juga nilai eksploitasi pada $P$. merguensis jantan belum mencapai nilai optimum.

\section{UCAPAN TERIMA KASIH}

Penulis menyampaikan ucapan terima kasih kepada semua pihak yang turut membantu dalam penelitian, terutama kepada orang tua, nelayan dan perangkat kantor kelurahan Senggarang beserta dosen pembimbing.

\section{REFERENSI}

Bittner, A., \& Ahmad, M. (1989). Budidaya Air. Seri Studi Pertanian. Kerjasama Jerman dan Indonesia. Yayasan Obor Indonesia.

Devi, C.B.L., Nair, K.C.C., Balasubramanian, T., Gopalakrishnan, T.C., Aravindakshan, P.N., \& Kutty, M.K. (1983). Length-Weight Relation and Condition Factor of Penaeus Indicus and Metapenaeus Dobsoni in the Cochin Backwater. MahasagarBulletin of the National Institute of Oceanography, 16(3): 399-402.

Effendie, M.I. (2002). Biologi Perikanan. Yayasan Pustaka Nusatama. Yogyakarta.

Fauzi, M., Prasetyo, A. P., Hargiyatno, T. I., Satria, F., \& Utama, A. A. (2013). Hubungan Panjang-Berat dan Faktor Kondisi Lobster Batu (Panulirus penicillatus) di Perairan Selatan Gunung Kidul dan Pacitan. Bawal, 5(2): 97-102.

Hargiyatno, I, T., Fijianggawangsa, R., \& Sumiono, B. (2015). Sebaran Spasio - Temporal Ukuran dan Densitas Udang Jerbung (Penaeus merguiensis de Man, 1907) di Sub Area Dolak, Laut Arafura (WPP - NRI 718). Jurnal Penelitian Perikanan Indonesia, 21(4): $261-269$.

Hidayat, D., Sasanti, A. D, \& Yulisman. (2013). Kelangsungan hidup, pertumbuhan dan efisiensi pakan ikan gabus (Channa striata) yang diberi pakan berbahan baku tepung keong mas (Pomacea sp). Jurnal Akuakultur Rawa Indonesia, 1(2): 161-172.

Naamin, N. (1984). Dinamika Populasi Udang Jerbung (Penaeus merguiensis de Man) di Perairan Arafura dan Alternatif Pengelolaannya (Disertasi). Institut Pertanian Bogor.

Nurdin, E., \& Kembaren, D.D. (2015). Parameter Populasi Udang Putih (Panaeus merguiensis) di Perairan Sempit dan sekitarnya, Kalimantan Tengah. Bawal, 7(2): 103-109.

Pauly, D. (1983). Some SimpleMethods for theAssessment of Tropical Fish Stocks. FAO Fisheries Technical Paper (254): 52.

Peter, J., Crocos, \& Kerr, J.D. (2003). Maturation and spawning of the banana prawn Penaeus merguiensis de Man (Crustacea: Penaeidae) in the Gulf of Carpentaria, Australia. Journal of Experimental Marine Biology and Ecology, (69): 37-59. 
Pramonowibowo, Hartoko, A., \& Ghofar, A. (2007). Kepadatan Udang Putih (Penaeus merguensis) di Sekitar Perairan Semarang. Jurnal Pasir Laut, 2(2): 18-29.

Pratiwi, R. (2008). Aspek biologi udang ekonomis penting. Jurnal Oseana, 33(2): 15-24.

Pratiwi, R., \& Widyastuti, E. (2013). Pola Sebaran dan Zonasi Krustasea di Hutan Bakau Perairan Teluk Lampung, Jakarta Utara. Zoo Indonesia: Jurnal Fauna Tropika, 22(1): 11-21.

Rahayu., \& Ennie, S. (2012). Kajian Stok Sumberdaya Ikan Kurisi (Nemipterus japonicus, Bloc 1792) di Perairan Selat Sunda yang Didaratkan Di PPI Labuan, Pandeglang, Banten. Institut Pertanian Bogor.

Saputra, S.W., Soedarsono, P., \& Sulistyawati, G.A.. (2009). Beberapa Aspek Biologi Ikan Kuniran (Upeneus spp.) di Perairan Demak. Jurnal Saintek Perikanan, 5(1): 1-6.

Saputra, S.W., Djuwito, \& Rutyaningsih, A. (2013). Beberapa Aspek Udang Jerbung (Penaeus merguiensis) di Perairan Pantai Cilacap Jawa Tengah. Journal of Management of Aquatic Resources, 2(3): 47-55

Saputra., \& Suradi, W. 2007. Buku Ajar Mata Kuliah Dinamika Populasi. Semarang: Universitas Diponegoro.

Sari, K.D., Saputra, S.W., \& Solichin, A. (2017). Aspek Biologi Udang Jerebung (Panaeus merguiensis de Man, 1888) di Perairan Kendal, Jawa Tengah. Journal of Maquares, 6(2): 128-136.

Sparre, P. \& S. Venema. (1999). Introduction to Tropical Fish Stock Assesment. (Introduksi Pengkajian Stok Ikan Tropis. Alih bahasa: Pusat Penelitian dan Pengembangan Perikanan). Buku 1: Manual. Badan Penelitian dan Pengembangan Perikanan. Jakarta: $438 \mathrm{p}$.

Subani, W., \& Barus, H.R. (1988). Alat penangkap ikan laut dan udang di perairan Indonesia. Jurnal Penelitian Perikanan Laut, (47):2130.

Suman, A., \& Satria, F. (2013). Strategi Pengelolaan Sumber Daya Udang Laut Dalam Secara Berkelanjutan di Indonesia. Jurnal Kebijakan Perikanan Indonesia, 5 (1):47-55.

Suman, A., \& Umar, C. (2010). Dinamika populasi udang putih (Penaeus merguiensis deMann) di Perairan Kotabaru, Kalimantan Selatan. J.Lit.Perikan Ind. Pusat Riset Perikanan Tangkap, 16(1): 29-33.

Syakila, S. (2009). Studi Dinamika Stok Ikan Tembang Provinsi Jawa Barat. Institut Pertanian Bogor.

Tirtadanu \& Ernawati, T. (2016). Kajian Biologi Udang Jerbung (Penaeus merguiensis De Man, 1888) di Perairan Utara Jawa Tengah. Bawal, 8(2): 109-116.

Wahyuni, I.I., Solichin, A., \& Saputra, S.W. (2017). Beberapa Aspek Biologi Udang Putih (Panaeus indicus) di Perairan Sebelah Utara Brebes dan Tegal, Jawa Tengah. Indonesia Journal of Fisheries Science and Technology, 13(1): 38-44.

Wedjatmiko \& Yulianti. (2013). Beberapa aspek Biologi Udang Jerbung (Penaeus Merguensis) di perairanMayangan, Pantai Utara Jawa Tengah. Jurnal Penelitian Perikanan Indonesia, 9(3), 27-34

Wedjatmiko. (2012). Strategi pengelolaan sumberdaya udang di perairan Selat Makasar. Jurnal Kebijakan Perikanan Indonesia, 4(1), 1725.

Widodo, J., \& Saudi. (2006). Pengelolaan Sumberdaya Perikanan Laut. Gajah Mada University Press. Yogyakarta. 